\title{
Stage II Chronic Maxillary Atelectasis Associated with Subclinical Visual Field Defect
}

\author{
João Mangussi-Gomes ${ }^{1}$ Márcio Nakanishi ${ }^{1}$ Maria Regina Chalita ${ }^{2}$ Fabiana Damasco ${ }^{1}$ \\ Carlos Augusto Costa Pires De Oliveira ${ }^{1}$
}

1 Department of Otorhinolaryngology, Head and Neck Surgery, University Hospital of Brasília, University of Brasília, Brasília/DF, Brazil

2 Department of Ophthalmology, University Hospital of Brasília,

University of Brasília, Brasília/DF, Brazil

\begin{abstract}
Address for correspondence João Mangussi-Gomes, MD, Department of Otorhinolaryngology, Head and Neck Surgery, University Hospital of Brasília, University of Brasília, SQN 409, Bloco Q, Apto 106, Asa Norte, Brasília/DF 70857-170, Brazil (e-mail: joaopauloemt@gmail.com).
\end{abstract}

Int Arch Otorhinolaryngol 2013;17:409-412.

\begin{abstract}
Introduction Chronic maxillary atelectasis (CMA) is characterized by a persistent decrease in the maxillary sinus volume due to inward bowing of its walls. According to its severity, it may be classified into three clinical-radiological stages.

Objective To report a case of stage II CMA associated with subclinical visual field defect.

Case Report A 34-year-old woman presented with a 15-year history of recurrent episodes of sinusitis and intermittent right facial discomfort for the past 5 years. She denied visual complaints, and no facial deformities were observed on physical examination. Paranasal sinus computed tomography (CT) demonstrated a completely opacified right maxillary sinus with inward bowing of its walls, suggesting the diagnosis of stage II CMA. A computerized campimetry (CC) disclosed a scotoma adjacent to the blind spot of the right eye, indicating a possible damage to the optic nerve. The patient was submitted to functional endoscopic sinus surgery, with drainage of a thick mucous fluid from the sinus. She did well after surgery and has been asymptomatic since then. Postoperative CT was satisfactory and CC was normal.

Discussion CMA occurs because of a persistent ostiomeatal obstruction, which

Keywords

- paranasal sinus diseases

- maxillary sinus

- visual fields

- maxillary diseases creates negative pressure inside the sinus. It is associated with nasosinusal symptoms but had never been described in association with any visual field defect. It can be divided into stage I (membranous deformity), stage II (bony deformity), and stage III (clinical deformity). The silent sinus syndrome is a special form of CMA. This term should only be used to describe those cases with spontaneous enophthalmos, hypoglobus, and/or midfacial deformity in the absence of nasosinusal symptoms.
\end{abstract}

\section{Introduction}

Chronic maxillary atelectasis (CMA) is characterized by a persistent decrease in the maxillary sinus volume due to inward bowing of its antral walls. ${ }^{1}$ Some confusion between CMA and silent sinus syndrome (SSS) exists in the literature. It is suggested, however, that SSS is a form of CMA., ${ }^{2,3}$ Indeed, according to its severity, CMA may be classified into three successive clinical-radiological stages: stage I, membranous deformity; stage II, bony deformity; and stage III, clinical deformity. ${ }^{1}$ Although CMA cases are always accompanied by nasosinusal symptoms, the term silent sinus syndrome should only be used when CMA presents with spontaneous enophthalmos, hypoglobus, and/or midfacial deformity in the absence complaints related to nose and paranasal sinuses. ${ }^{2}$

Some authors affirm that CMA and SSS are never associated with visual field impairment. ${ }^{4}$ We present a very received

November 25, 2012

accepted

April 29, 2013
Copyright (C 2013 by Thieme Publicações DOI http://dx.doi.org/ Ltda, Rio de Janeiro, Brazil $10.1055 / \mathrm{s}-0033-1351679$. ISSN 1809-9777. 


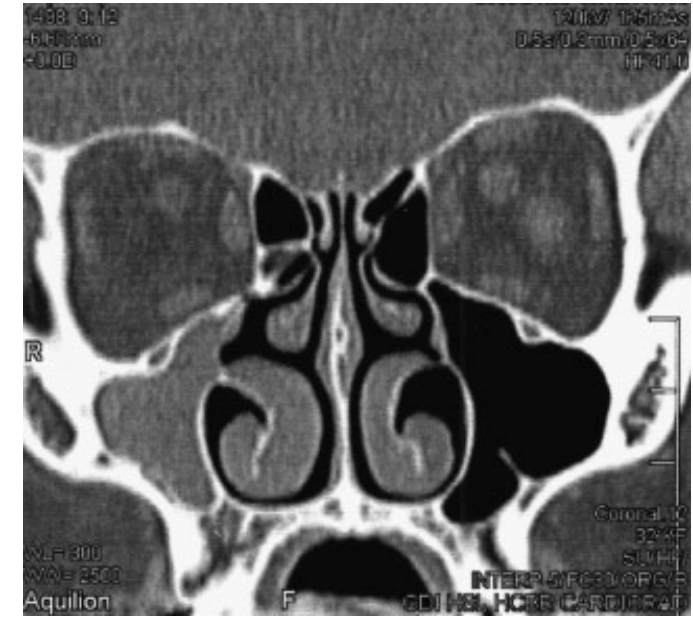

Fig. 1 Coronal computed tomography of the nose and paranasal sinuses demonstrates total opacification of the right maxillary sinus. Inward bowing of the medial, superior, and posterolateral walls may also be seen.

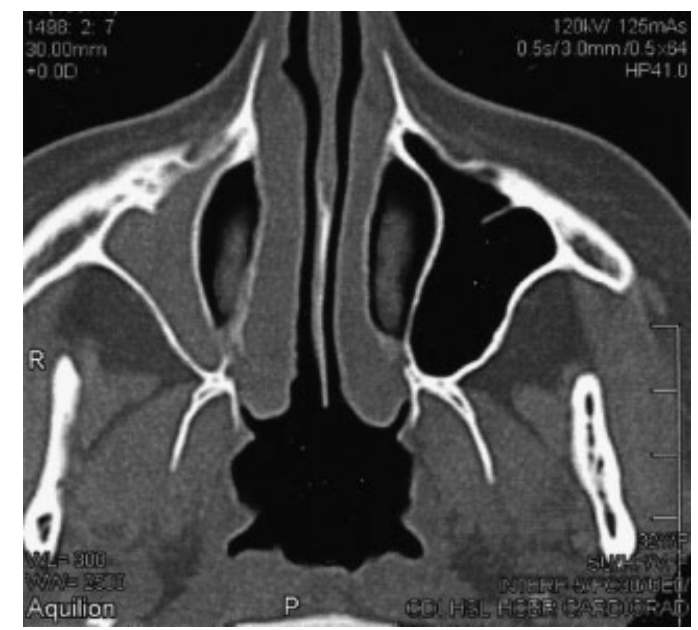

Fig. 2 Axial computed tomography of the nose and paranasal sinuses demonstrates total opacification and contraction of right maxillary sinus. illustrative case of stage II CMA associated with subclinical visual field impairment, which completely resolved after surgery.

\section{Case Report}

A 34-year-old woman presented to the otolaryngology clinics complaining of recurrent episodes of maxillary acute rhinosinusitis, accompanied by facial pain, nasal congestion, and rhinorrhea, for more than 15 years. For the past 5 years, nasosinusal symptoms had partially improved but intermittent and progressive right facial discomfort had developed. General and otolaryngologic physical examinations were unremarkable, except for hyperesthesia to light touch on right malar region. Computed tomography (CT) of the paranasal sinuses was therefore performed (-Figs. 1 and $\mathbf{2}$ ).

Despite not complaining of visual symptoms, a complete ophthalmologic evaluation was also undertaken. Computerized campimetry (CC) disclosed a scotoma adjacent to the blind spot of the right eye (-Fig. 3). Clinical enophthalmos, hypoglobus, and/or facial deformity were not present and the remainder of the ophthalmologic assessment was normal.

Based on her clinical and radiologic presentation, she was diagnosed with stage II CMA. She was submitted to functional endoscopic sinus surgery, which included right uncinectomy, bullectomy, and maxillary antrostomy. During the procedure, a thick mucous fluid was aspirated from inside the affected sinus. She did well after surgery and radiologic controls were satisfactory (-Fig. 4). The visual field defect completely resolved, and the patient has been asymptomatic during a 3-year follow-up period.

\section{Discussion}

CMA is an acquired and unusual condition that refers to a persistent and progressive decrease in maxillary sinus volume due to an inward bowing of its antral walls. ${ }^{1,2}$ It seems to affect patients in their late 30s or early 40 s, with no gender preference and similar incidences in left and right sides. ${ }^{2}$
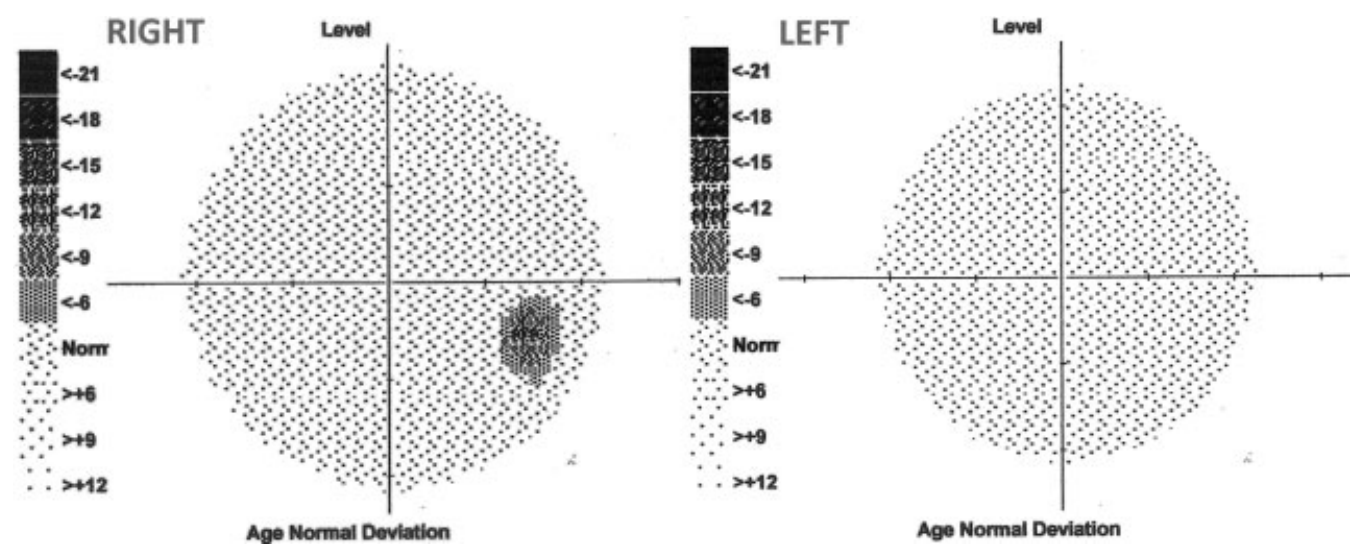

Fig. 3 Computerized campimetry shows a scotoma adjacent to the blind spot of the right eye, possibly indicating damage to the ipsilateral optic nerve. 


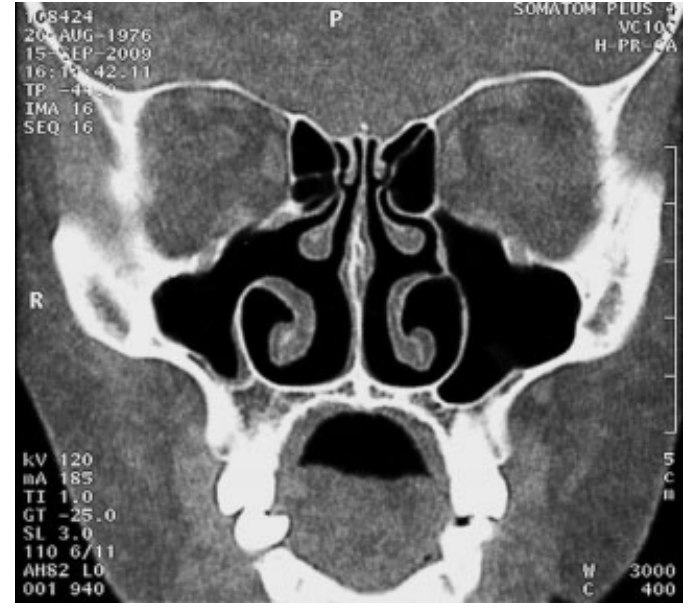

Fig. 4 Postoperative coronal computed tomography of the nose and paranasal sinuses. Wide maxillary antrostomy can be appreciated.

The etiology and physiopathology of CMA are not completely elucidated. It is thought that CMA is an acquired and progressive phenomenon. ${ }^{5,6}$ The process is probably initiated by a sustained obstruction of the maxillary sinus at the level of the ostiomeatal complex. The resulting hypoventilation of the maxillary sinus leads to gas absorption by the sinus mucosa, generating negative pressure inside the sinus. Consequent accumulation of mucus and chronic subclinical inflammation of the mucosa are responsible for the resorption and remodeling of the adjacent bony walls. Maxillary sinus atelectasis would then occur as a result of the created gradient of pressure acting over osteopenic sinus walls. ${ }^{3,7-9}$

Clinical presentation of CMA varies according to duration and severity of the disease. ${ }^{1,5}$ In initial phases, clinical deformities are absent and the diagnosis of CMA is only suggested by characteristic CT findings, which include obstruction of ethmoidal infundibulum and total or near total opacification of sinus content. Variable degrees of inward bowing of sinus walls are also seen. ${ }^{1,5,9-11}$

In advanced cases, however, CMA presents with evident facial deformity, enophthalmos and/or hypoglobus as major complaints. CT scans reveal the associated severe changes to the maxillary sinus anatomy in these situations. When enophthalmos and/or hypoglobus are present, important orbital floor displacement into the sinus lumen and orbital volume enlargement are found on CT images. ${ }^{5,9,10}$
Considering its clinic-radiological evolution, CMA can be broken down into three stages, which represent the spectrum of the disease ${ }^{1}$ : stage I, membranous deformity with lateralized soft medial wall; stage II, bony deformity with inward bowing of superior, anterior, and posterolateral osseous walls; stage III, clinical deformity with apparent facial asymmetry, enophthalmos, and/or hypoglobus.

CMA is also accompanied by symptoms related to the nose and paranasal sinuses, including facial pain, discomfort or pressure, headaches, congestion, and/or rhinorrhea. Interestingly, nasosinusal symptoms are inversely related to the severity of maxillary sinus deformity. ${ }^{1,5}$ Although early stages of CMA (stages I and II) are usually associated with history of nasosinusal symptoms, late-stage CMA (stage III) is often asymptomatic at the time of the diagnosis. It is theorized that in advanced cases the absence of important nasosinusal symptoms in initial phases and in the course of the disease would explain the delayed diagnosis and more pronounced bony and aesthetical deformities. ${ }^{1,2,5,12}$

Considering these aspects, when CMA presents with progressive development of facial asymmetry, enophthalmos, and/or hypoglobus, without past or present history of symptoms related to the nose and sinuses, it should be called silent sinus syndrome. Since this term was coined, SSS and CMA have been described independently in the literature, as if it were completely different conditions. ${ }^{13}$ Despite that, recent reviews of the literature have indicated that SSS and stage III CMA have the same proposed etiology, pathophysiology, and radiologic features. ${ }^{10,11}$ Hence, SSS should be considered a quite singular and special form CMA and should be included in the spectrum of the disease, as shown in - Table 1. ${ }^{2,3}$

In the case we reported, because the patient presented with subclinical maxillary sinus contraction and opacification, evidenced by CT images, along with past and present history of nasosinusal symptoms, she was better diagnosed with stage II CMA. The diagnosis of SSS would not fit for this case.

Interestingly, subclinical visual field impairment was objectively evidenced by CC in the case presented. We hypothesize that because of the contraction of the maxillary sinus there is a consequent descent of the ipsilateral orbital floor and a possible transmission of the negative pressure from the sinus into the orbit. This could impair the vasa nervorum blood flow and subsequently cause a transient ischemic injury to the optic nerve. ${ }^{14}$ Visual field defect resolved completely after surgery and this would corroborate this

Table 1 Spectrum of the disease CMA/SSS

\begin{tabular}{|l|l|l|l|l|}
\hline CMA & Stage I & Stage II & Stage III & SSS \\
\hline Terminology & $\begin{array}{l}\text { Membranous } \\
\text { (soft medial wall) }\end{array}$ & $\begin{array}{l}\text { Bony } \\
\text { (osseous walls) }\end{array}$ & $\begin{array}{l}\text { Clinical (enophthalmos, } \\
\text { hypoglobus, facial asymmetry) }\end{array}$ \\
\hline Deformity & +++ & ++ & + & - \\
\hline
\end{tabular}

Abbreviations: CMA, chronic maxillary atelectasis; SSS, silent sinus syndrome.

${ }^{a}$ The diagnosis and differentiation of both conditions are based upon history, physical examination, and characteristic radiological findings. ${ }^{1-3}$ 
hypothesis. This is the first case of CMA so far to be described in association with some sort of visual field impairment and possible damage to the ipsilateral optic nerve. ${ }^{4}$

CMA/SSS is better managed in a two-step manner. It is first mandatory to relieve the obstruction of the maxillary sinus and restore its normal ventilation. This is usually achieved via functional endoscopic sinus surgery. During the procedure, as the orbital floor and the uncinate process are usually lower and more lateralized, respectively, special attention must be kept not to damage orbital content. ${ }^{3,4,8}$ The second step consists of correcting clinical deformities whenever present. Reconstruction of the orbital floor is the most commonly performed procedure and various techniques are available for this purpose. As spontaneous resolution of clinical deformity may occur after adequate aeration of the sinus, waiting a few months between the two surgical approaches is highly recommended. $2,4,15$

\section{Conclusion}

We described a very illustrative case of stage II CMA. It seems to be the first case of CMA associated with any sort of visual field impairment to be reported in literature. SSS is considered a form of CMA. We highlight the importance of the correct diagnosis and differentiation between these terms.

\section{References}

1 Kass ES, Salman S, Rubin PA, Weber AL, Montgomery WW. Chronic maxillary atelectasis. Ann Otol Rhinol Laryngol 1997;106: 109-116
2 Brandt MG, Wright ED. The silent sinus syndrome is a form of chronic maxillary atelectasis: a systematic review of all reported cases. Am J Rhinol 2008;22:68-73

3 Hunt SM, Tami TA. Sinusitis-induced enophthalmos: the silent sinus syndrome. Ear Nose Throat J 2000;79:576, 579-581, 584

4 Annino DJ Jr, Goguen LA. Silent sinus syndrome. Curr Opin Otolaryngol Head Neck Surg 2008;16:22-25

5 Ende K, Mah L, Kass ES. Progression of late-stage chronic maxillary atelectasis. Ann Otol Rhinol Laryngol 2002;111:759-762

6 Davidson JK, Soparkar CN, Williams JB, Patrinely JR. Negative sinus pressure and normal predisease imaging in silent sinus syndrome. Arch Ophthalmol 1999;117:1653-1654

7 Kass ES, Salman S, Montgomery WW. Manometric study of complete ostial occlusion in chronic maxillary atelectasis. Laryngoscope 1996;106:1255-1258

8 Numa WA, Desai U, Gold DR, Heher KL, Annino DJ. Silent sinus syndrome: a case presentation and comprehensive review of all 84 reported cases. Ann Otol Rhinol Laryngol 2005;114:688-694

9 Gaudino S, Di Lella GM, Piludu F, et al. CT and MRI diagnosis of silent sinus syndrome. Radiol Med (Torino) 2013;118:265-275

10 Illner A, Davidson HC, Harnsberger HR, Hoffman J. The silent sinus syndrome: clinical and radiographic findings. AJR Am J Roentgenol 2002;178:503-506

11 Wise SK, Wojno TH, DelGaudio JM. Silent sinus syndrome: lack of orbital findings in early presentation. Am J Rhinol 2007;21:489-494

12 Borin A, Cruz OLM, Figueiredo CR. [Síndrome do seio silencioso, uma entidade pouco conhecida: relato de dois casos clínicos e revisão de literatura]. Braz J Otorhinolaryngol 2005;71:26-31

13 Soparkar CN, Patrinely JR, Cuaycong MJ, et al. The silent sinus syndrome. A cause of spontaneous enophthalmos. Ophthalmology 1994;101:772-778

14 Thawley SE. The otolaryngologist-ophthalmologist relationship: an historic perspective. Otolaryngol Clin North Am 2006;39:845-853

15 Sivasubramaniam R, Sacks R, Thornton M. Silent sinus syndrome: dynamic changes in the position of the orbital floor after restoration of normal sinus pressure. J Laryngol Otol 2011;125: 1239-1243 